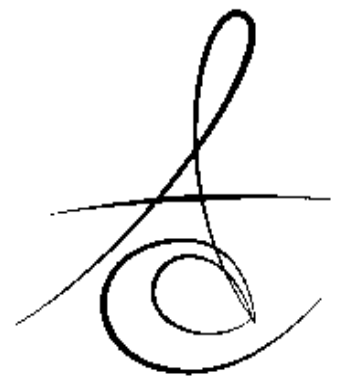

\title{
GEÇMİŞTEN GÜNÜMÜZE POLİMERİZASYON CİHAZLARI
}

POLYMERIZATION LIGHT-CURING UNITS FROM PAST TO PRESENT

\author{
Dr.Özge TÜRKOĞLU*
}

Dr. Öğr. Üyesi Ali Can BULUT*

Makale Kodu/Article code: 3264

Makale Gönderilme tarihi: 04.01.2017

Kabul Tarihi: 14.02.2017

\section{öz}

Görünür ışıkla sertleşen kompozit rezinlerin polimerizasyonu için ışık cihazları kullanılmaktadır. Kompozit rezinlerin içeriğinde olduğu gibi piyasaya çıkarılan ışık cihazlarında da çeşitlilikler olmuştur. Uygulama zamanını azaltmak ve polimerizasyon miktarını arttırmak için kullanılan teknolojiler ve teknikler zaman içerisinde değişim göstermektedir. İlk geliştirilen ultraviyole ışık cihazından günümüze kadar; kuartz tungsten halojen ışık cihazları (QTH), light emitting diode (LED), plazma ark ışık cihazları (PAC), argon lazer ışık cihazları olmak üzere farklı tipte ışık kaynakları geliştirilmiştir.

$\mathrm{Bu}$ derlemenin amacı günümüzde kullanılan ışık cihazlarının özelliklerini, çalışma prensiplerini ve polimerizasyon etkinlikleri hakkında güncel çalışmalar ışı̆ında bilgi vermektedir.

Anahtar Kelimeler: Halojen ışık cihazları, Işık cihazları, Lazer, LED, PACı

\section{ABSTRACT}

Light curing units are used polmerization for lightcured composite resins. Content of composite resins as well as light curing device has been varied. Using technologies and techniques to reduce the time aplication and increase the amount of the polimeriztion has changed over time. From the first developed device ultraviolet up to the present, quartz-tungstenhalogen light-curing units (QTH), light emitting diode (LED), plasma arc light devices (PAC), argon laser light devices have been developed, including different types of light sources.

The aim of this review is to present the properties of the light equipment, working principles and in the light of recent studies provide information about the activities of polymerization.

Key Words: Halogen lamp, Light-curing unit, Laser, LED, PAC

waals bağlantıları yıkılır ve polimer ağı oluşturan kovalent bağlar kurulur. Polimerizasyon büzülmesi kaçınılmaz olarak bu sırada oluşur. Polimerizasyon sağlanmasında ışık kaynağının 'Işık Şiddeti yada yoğunluğu' ve 'Toplam Enerji Yoğunluğu' kompozit rezinlerin fiziksel özelliklerini etkileyen faktörlerdendir. Işık şiddeti yada yoğunluğu $\left(\mathrm{mW} / \mathrm{cm}^{2}\right)$; birim alana düşen ışık gücüdür (miliwatt). Komozit rezinlerin polimerizasyonu için en az $400 \mathrm{~mW} / \mathrm{cm}^{2}$ ışık yoğunluğu önerilmiştir. Işık ucu çapı daha büyük olan ışık cihazlar daha fazla güce sahiptir. Ancak ışık ucundan uzaklaştıkça ışığın yayıldığı birim alan daha büyük olduğu için ışık yoğunluğu daha az olur. ${ }^{3-6}$

*Kıııkkale Ağız Diş Sağlığı Merkezi, Restoratif Diş Tedavisi Uzmanı

** Kırıkkale Üniversitesi Diş Hekimliği Fakültesi Protetik Diş Tedavisi 
Polimerizasyon boyunca kompozit rezine uygulanan toplam enerjiye 'Toplam Enerji Yoğunluğu' denir ve ışık yoğunluğu $\left(\mathrm{mW} / \mathrm{cm}^{2}\right)$ ile uygulama süresinin (sn) çarpımıdır. Birimi $\left(\mathrm{mJ} / \mathrm{cm}^{2}\right)$ dır. ${ }^{7,8}$ Kompozit rezinlerinin polimerizasyonunda oldukça önemli bir kavramdır. Orantılı olarak yüksek ışık şiddetinin kısa süreli uygulanması ile düşük ışık şiddetinin uzun süreli uygulaması ile eşit polimerizasyon derecesinin sağlanabileceği düşünülmektedir. ${ }^{9,10}$

Ultraviyole spekturumu (UV), elektromanyetik spektrumun görünür ışıktan daha kısa olan 10-380 $\mu \mathrm{m}$ dalga boyundaki bir parçasıdır. Günümüzde görünür ışık cihazlarında insan beyni tarafından görüntü (renk) haline çevrilebilen elektro manyetik spektrumun 400$700 \mu \mathrm{m}$ dalga boyundaki bölümünün mavi ucunda, mavi yeşil sınıındaki ışık kullanılmaktadır. ${ }^{11,12}$

Görünür ışığın her renk aralığında; dalga boyu, ışı̆ın gücü, ışıma miktarı ve yoğunluğu, yüzey alanına düşen güç değişmektedir. Dalgalar halinde olan ışıma, yayılım yolu boyunca karşılaştığı partiküllerle çarpışır, absorbe edilir veya yansır hatta kırılır. Havada yada materyalin içinde dalga formunda ilerleyen ışımadaki fenomen, güç yada yoğunluğun azalmasına sebep olur.

İstenilen noktaya istenilen miktarda ışımanın oluşması birçok faktöre bağıdır. Bunlar ışık uygulama süresi, materyalle ışık kaynağı arasındaki mesafe, polimerizasyon derinliği, ışık kaynağı ile hedef materyal arasındaki elementler, ışık şiddeti ya da yoğunluğudur. ${ }^{13}$

Temelde bir ışık cihazı tasarımı; ana kutu, ışık kaynağı, belirli dalga boyundaki ışığın geçişini sağlayan filtreler ve ışığı uygulama bölgesine taşıyacak fiber optik ileticiden oluşmaktadır. Işık cihazları, tezgah üstü tip, tabanca tipi ünite ve fiber optik ek üniteler den oluşmaktadır.4,14

\section{Tezgah Üstü Tip}

Bütün fonksiyonel parçalar (ışık kaynağı, fan, filtre, polimerizasyon süresini gösteren zaman ölçer ve transformatörler) bir ana kutudadır. Bu kutudan ışık uygulama bölgesine ya cam fiberden oluşan, rijit fiber optik kabloyla ya da akışkan dolgulu, transparan bir dolgu içeren esnek bir kablo olmak üzere iki tip aparatla taşınabilir. Ana kutuda fonksiyonel parçaların ve fan sisteminin bulunması ile bu parçalar operasyon sahasının dışında bırakılmış olur ki bu tip tasarımlar piyasada daha ucuz satışa sunulan modellerdir. ${ }^{15}$

Tabanca Tipi Üniteler

Işık kaynağı, filtreler ve fiber optik kısım tabanca şeklindeki el aparatındadır ve hareketli bir ünitedir. Çeşitli çap ve eğimlerden oluşan fiber uçların kullanımı için uygundur. Işık küçük fiber optik kort ya da namlu görünümündeki saydam yol boyunca iletilir. Değişik çapta fiber uçlar uygulanabilir. Geniş çaplı uç ile uygulandığında iyi bir yoğunluk oluşur. Sesli çalışan fanın, tabanca şeklindeki el aparatında bulunması nedeni ile uzun süreli kullanımlarda ısınma meydana gelir ve buna bağlı olarak gürültülü çalışır. Pahalı bir cihazdır. Tabancanın büyük ve ağır olması bu cihazın dezavantajlarındandır. ${ }^{13,15}$

\section{Fiber Optik Ek Ünite}

Fiberoptik ek uçları el aparatındaki ışık kaynağına uygulanır. Uygulama uçları tezgah üstü modelindekine benzer fakat daha küçüktür. Mavi ışık filtresi yıpranmış ya da etkisini yitirmiş üniteler de belirgin ISI oluşturur. Oldukça küçük ve çok az yer kaplayan bu ek üniteler el aletinden daha ucuzdur. Küçük çaplı uçlar kullanılması, az ışık yoğunluğuyla uygulanması, bazı modellerde aşırı ISı oluşması ve yenilenme zorluğu en büyük dezavantajıdır. ${ }^{13,15}$

\section{Polimerizasyon Cihazları}

Polimerizasyon amacıyla kullanılan ilk ışık ünitesi UV ışık cihazıdır. Kompozit rezinlerdeki ve mikro elektronik teknolojisindeki gelişmelere paralel olarak bugün farklı mekanizmalara sahip; spektral dağılım, aydınlanma şiddeti ve radyasyon şiddeti açısından farkIılıklar gösteren görünür ışık cihazları kullanılmaktadır. ${ }^{1,10,13}$

\section{UV Işık Ünitesi}

Işıkla aktive olan ilk kompozitlerde kullanılan foto başlatıcıyı, benzoin metil eteri aktive eden ilk ışık cihazdır. 320-365 $\mu \mathrm{m}$ dalga boyunda görünür olmayan ultraviyole ışığı kullanılmıştır.

Materyalin yüzey tabakasında yüksek oranda sertleşme sağlamaları ve materyallerin renk değişimlerini önlemeleri, bu cihazların avantajları olarak söylenebilir. ${ }^{6,14}$

UV ışık, hasta ve hekim için zararlıdır. Bazı cilt kanserlerine ve hastalıklarına, göz lensinin hasarına, gözde katarak veya göz damarlarının genişlemesine ve çeşitli mutojenik etkilere yol açabilmektedir. Ayrıca foto-toksik etkisi vardır. ${ }^{6,14}$ Bu dezavantajları nedeniyle UV ışık kaynakları yerini görünür mavi ışık kaynaklarına bırakmıştır. Günümüzde klinik uygulamalarda kullanılmamaktadır. ${ }^{6,14}$ Ancak UV cihazlar filtreli (1014mW/ $\mathrm{cm}^{2}$ ) olarak, diş laboratuvarlarında rezinlerin indirekt polimerizasyonlarında kullanılmaktadır. ${ }^{6,14}$ 


\section{Günümüzde Rezin İçerikli Materyallerin Polimerizasyonları İçin Kullanıma Sunulan Işsk Cihazları}

Günümüzde farklı teknik özelliklere ve avantajlara sahip çeşitli görünür ışık kaynakları kullanımaktadır. Bu cihazlar isimlerini ışığın üretildiği ışık kaynaklarından alıılar. Işık cihazlarının ortak dezavantajı materyalin birden sertleşmesine neden olurlar ve kompozit rezinde polimerizasyon büzülmesi oluşur. Bu nedenle kullanılan ışık cihazlarının hiçbiri ideal polimerizasyon oluşturacak optimal özelliklere sahip değildir. Çeşitli ışık kaynakları arasındaki ana farklııklardan biri ışık yoğunluğudur. Işık yoğunluğu cihazlar arasında 400 $\mathrm{mW} / \mathrm{cm}^{2}$ 'den $3200 \mathrm{~mW} / \mathrm{cm}^{2}$ 'ye kadar değişebilir. ${ }^{16-18}$

- Quartz Tungsten Halojen Işık Kaynakları (QTH),

- Plasma Ark Işık Polimerizasyon Cihazları (PAC),

- Işık Yayan Diyotlar (Light Emitting Diodes: LED),

- Lazer Işık kaynakları'dır. ${ }^{19,20}$

\section{Halojen Lambalar (QTH)}

Geçmişten günümüze polimerizasyon cihazları arasında en yaygın ve rütin olarak kullanılan ışık cihazlarıdır. ${ }^{21}$ Halojen lambalar gelişmiş akkor ampullerdir. Elektirik akımı elektronların birleştiği tungstren den yapılmış bobin üzerinden geçirilir. $2000-3000{ }^{\circ} \mathrm{C}$ ye kadar ısındıktan sonra akkorlaşıp parlamaya başlar. ${ }^{13,22}$ Halojen lambalarda oluşan ISı çok yüksek olduğu için kullanılan ampül, akkor ampüllerden daha küçük ve cam kalınlığı daha fazladır. Bu lambaların kullanım ömrü 100 saat ile sınırlıdır ve değişimi gerektirir. ${ }^{23}$ (Resim 1)

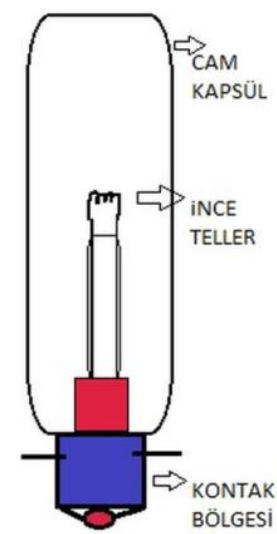

Şekil 1. Halojen lambalarının şematik yapısı.

Lambanın total çıkış gücünün sadece belirli bir kısmı bu cihazlarda polimerizasyon amacı için kullanımaktadır. ${ }^{24}$ Bu cihazlarda etkili ışık gücü 300-600 $\mathrm{mW} / \mathrm{cm}^{2}$ arasındadır. Halojen ışık cihazları ışığın çıkış gücünün arttırılabilmesi, farklı çıkış güçlerindeki ışığın, aynı cihazla değişik sürelerde uygulanabilmesi nedeniyle günümüzde rutin olarak kullanılan, maliyetlerinin diğer cihazlara oranla daha düşük olması nedeni ile en yaygın kullanılan ışık cihazlarıdır. ${ }^{24,25}$

Gelişen teknoloji ile halojen ampullerin güçlerinin artırımasına paralel olarak, ışık gücü 800-1000 $\mathrm{mW} / \mathrm{cm}^{2}$ 'nin üzerinde yüksek enerji yoğunluğu meydana getiren, daha kalın kompozit tabakalarının daha kısa sürede polimerizasyonunu sağladığı iddia edilen halojen ışık cihazları geliştirilmiştir. ${ }^{22,25}$ Ersoy ve ark. (2007) yaptıkları çalışmada halojen ışık kaynağının klinik olarak başarılı olduğunu göstermişlerdir. ${ }^{26}$

\section{LED (Light Emitting Diode) Ișık Cihazı}

Işık yayan diode olarak bilinen LED'ler, kuantum mekaniği etkisi ile görünür mavi ışı üreten ışık cihazlarıdır. Kuartz tungsten halojen lambaların bazı dezavantajlarını ortadan kaldırmak amacı ile geliştirilmiştir. 27,28

Temelde halojen lambalarda kullanılan sıcak filamenlerin yerine, elektronların birinden diğerine geçişine olanak veren iki ayrı yarı iletken kristal bulundurur ve farklı elektron yoğunluğuna sahiptirler. Biri ' $n$ ' diğeri ' $p$ ' olarak isim alır. Elektrik akımı bu kristal parçalardan geçirildiğinde elektronlar ve boşluklar birleşir ve ' $p n^{\prime}$ arasında enerji oluşur. Kullanılan kristale göre değişen dalga boyunda görünür ışık elde edilir. ${ }^{27,29}$ (Şekil 2) LED ışık cihazlarının temel özelliği 400-500 $\mu \mathrm{m}$ dalga boyu aralığında, sadece görülebilir ışık üretmeleridir. Etkin spektrumları ise 450-490 $\mu \mathrm{m}$ dalga boyundadır. ${ }^{5,28}$ Cihazın emisyon profili ile uyumlu soğurma özelliği olan foto başlatııısı kamferokinondur. 440-490 $\mu \mathrm{m}$ arasındaki dalga boyu kamferokinon içeren kompozit rezinlerde polimerizasyon için yeterlidir. ${ }^{30}$

Filtrelenme gereksinimi olmadan istenilen dalga boyundaki ışık üretilir. Enerji kaybı oldukça azdır. Elde edilen enerjinin hemen hemen hepsi polimerizasyon için kullanılabilmektedir. Bu nedenle cihazların elektrik enerjisi tüketimleri daha azdır.1-4 volt arasında değişik voltaj ve 10-40 miliamper arasında elektrik enerjisi ile Işık üretebilir. ${ }^{31,32}$

İşlem sırasındaki yüksek ISı oluşumu gibi QTH ışık cihazlarındaki problemleri gidermek ve etkinliği arttırmak amaciyla 1995 yilında Light emitting diode (LED) ışık cihazları alternatif olarak sunulmuştur. ${ }^{30-33}$

İlk üretilen LED ışık kaynakları QTH ışık cihazlarından daha az ısı açığa çıkardıklarından kullanımları sırasında gingival ve pulpalda daha az irritasyona neden olmaktadır. ${ }^{32,34}$ Kullanılan lambanın, ömrü

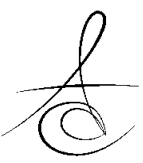


yaklaşık 10.000 saattir. Kullanımla birlikte ışık yoğunluğu zaman içinde azalmaz. Lambalarının yenilenmesinin maliyeti düşüktür. Bu cihazların ampullerinin ömrünün uzun olması, düşük enerji tüketimleri sayesinde şarj edilebilmeleri, kablosuz ve portatif düzenekleri, ürettikleri ısının halojenlere kıyasla daha az olması gibi avantajları vardır. ${ }^{23,24}$

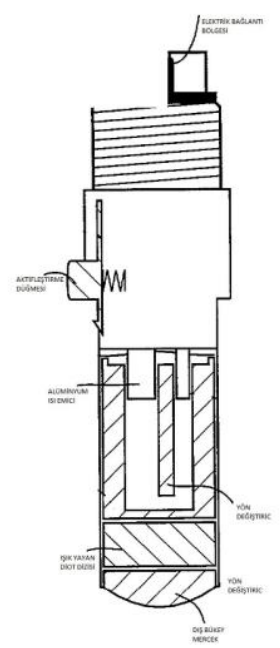

Şekil 2. Led ampülünün şematik yapısı.

\section{Birinci nesil LED ışık cihazları:}

Birinci nesil LED'ler piyasaya ilk çıkan jenerasyondur. QTH ışık cihazlarının dezavantajlarını gidermek amacıyla üretilmişlerdir. Performansları halojen ışık kaynakları ile hemen hemen aynıdır. ${ }^{19}$ Işık yoğunluğu $400 \mathrm{mw} / \mathrm{cm}^{2}$ ile sınırlı olduğu için 40 sn yada daha uzun ışık uygulama süresi vardır. ${ }^{35}$ İlk üretilen LED ışık cihazlarının, kompozit rezinleri yeterli derecede polimerize edemediğini gösteren çalışmalar vardır. Bunun sebebinin ilk kullanılan LED’lerin düşük ışık yoğunluğu ( $400 \mathrm{~mW} / \mathrm{cm}^{2}$ ) ve sınırlı dalga boylarına sahip olmaları olarak bildirilmiştir. Kompozit rezinlerin koyu renklerinde uygulama süresinin arttırılmasına karşın diğer ışık kaynaklarından elde edilen polimerizasyon oranını sağlayamamıştır. Çakmakcıkoğlu ve ark. (2005) yaptıkları bir çalışmada birinci nesil LED’lerin klinik olarak yetersiz olduklarını göstermişlerdir. ${ }^{36}$

\section{İkinci nesil LED ışık cihazları:}

Uygulama süresini azaltmak amacıyla ışık yoğunluğu arttırılmış (1200-1500 mW/cm²) olan ikinci nesil LED ışık cihazları geliştirilmişitir. Bu cihazlar yüksek ışık yoğunluğunda, birinci nesilde olduğu gibi dar Işık spekturumuna sahip (390-490 $\mu \mathrm{m}$ dalga boyunda) mavi ışık üretmektedir. ${ }^{37,38}$
1995 yılında $280 \mathrm{~mW} / \mathrm{cm}^{2}$ ışık gücündeki birinci nesil LED ışık kaynağı ile 60 sn ışık uygulaması tavsiye ediliyorken, günümüzde yüksek ışık şiddeti nedeni ile ikinci nesil LED'lerle polimerizasyon için gereken uygulama süresini 20 saniyenin altına düşürebilmektedir. Hekim ve hasta için tedavi süresini azaltması en büyük avantajlarındandır. ${ }^{37}$

Kamferokinon dışındaki diğer fotoaktivatörler, $410 \mu \mathrm{m}$ dalga boyundaki ışığa daha hassas ve 450-480 $\mu \mathrm{m}$ dalga boyu arasındaki ışığa ise daha az hassas mono asilfosfin oksit (Lucirin TPO) veya 1-Fenil 1,2Propandiyon (PPD) dur. ${ }^{38,39}$

Bu nedenle birinci ve ikinci nesil LED ışık kaynakları, yapılarında kamferokinon dışındaki reaksiyon başlatıcıları içeren kompozit rezinler üzerine etkili olmayabilmektedir. Etkili polimerizasyon sağlamak amacıyla LED ışık kaynakları kullanılacağı zaman, polimerize edilecek restoratif materyalin yapısı iyi bilinmelidir. ${ }^{20}$

\section{Üçüncü nesil LED ışık cihazları}

Son yıllarda uygulama zamanını azaltmada daha da etkili olan; ışık yoğunluğu arttırımış üçüncü nesil LED ışık cihazları kullanıma sunulmuştur. ${ }^{40}$ Çoklu dalga boyuna sahip olan üçüncü nesil LED ışık cihazları kamferokinon dışındaki polimerizasyon başlatıcılarının da polimerize edilebilmektedir. ${ }^{41}$ Kamferokinonu aktive eden ikinci nesil ile ayn tipe sahip bir adet LED ampul ve diğer polimerizasyon başlatıcılar için daha düşük güçte chip kullanılan viyole spektrumunda ışık üreten dört adet aksesuar LED ampulden oluşmuştur. Çoklu diode kullanılan 3. nesil LED ışık cihazlarının, farklı çeşitlerdeki polimerizasyon başlatıcılarını polimerize edebileceği ifade edilmektedir. ${ }^{41}$

3.nesil LED ışık cihazlarının dental restoratif materyallerin her tipinde yeterli polimerizasyonunu sağladığını bildirmiştir. ${ }^{40,42}$

Labrie ve arkadaşları (2011) maksillar kesici dişe $30 \mathrm{~cm}$ den PAC (Sapphire, Den-Mat Santa Maria, CA ), düşük güçlü LED (SmartLite IQ2; Caulk Dentsply Woodbridge), yüksek güçlü LED (Elipar S103; M ESPE London, ON) ve QTH (Optilux 501Kerr Corporation Orange, CA) ışık cihazı kullandıkları çalışmasında spektral emisyonu şekil 3 deki gibi bulmuşlar, Mavi ışığın yüksek güçteki ışık cihazlarının kısa mesafeden (0$30 \mathrm{~cm}$ ) uygulamalarında uygulayıcıda göz hasarı oluşturabileceğini bu nedenle koruyucu gözlük kullanımını tavsiye etmiştir. ${ }^{43}$ 


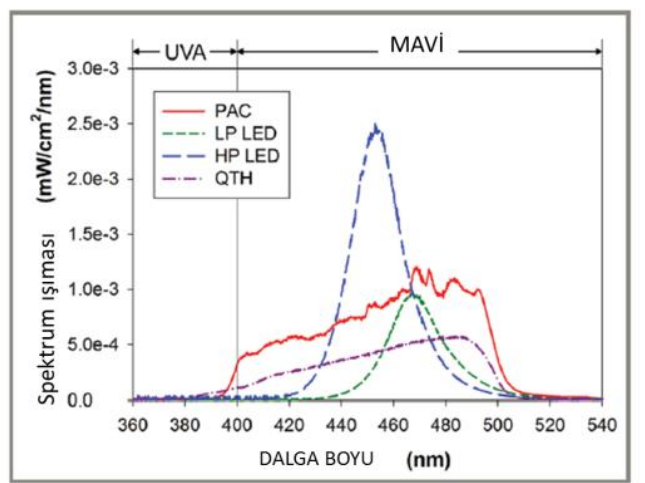

Şekil 3: Spektrum ışıması ( PAC:plazma ark ışık cihazı, LP LED: Düşük güçte LED, HP LED: Yüksek güçte LED, QTH: kuartz tungsten ışık cihazı

\section{Plazma Ark Işık Kaynakları}

Plazma ark ışık kaynaklarında xenon plazma kısa ark lambası kullanılır. Birbirinden ayrı iki tungstren elektrotun bulunduğu inert gaz dolu basınçlı bir hazneden oluşmaktadır. Bu elektrotlar arasından yüksek voltajlı elektrik akımı geçirilerek bir kıvııım oluşturulur ve ksenon gazı (inert gaz) iyonize edilir ve elektronlarla, pozitif iyonların bir karışımı oluşur. Bu oluşan yapı maddenin katı sıvı ve gaz fazına ek olan, dördüncü fazı yani plazma halidir. ${ }^{1,6}$ Böylece çok yüksek seviyelerde enerji oluşturulur. PAC üniteleri $1000 \mathrm{mw} / \mathrm{cm}^{2}$ den daha yüksek ışık üretilebilmektedir. $470 \mu \mathrm{m}$ dalga boyunun yakınında dar bir dalga boyu aralığında görünür ışık kısa bir süre için oluşur ve dar dalga boyu bandı CQ dışındaki diğer başlatıııları aktive edemeyebilir. ${ }^{44}$ Plazma Ark lambaların kullanım ömrü 500-5000 saat ile sınırlıdır.

PAC cihazlarında, halojen lambalardan daha geniş enerji spektrumu oluşturmaktadır. UV, görünür ışık ve kızı̈̈tesi ışık üretir. İstenmeyen ve zararı olan dalga boylarını elemine etmek amacı ile filtre sistemi kullanılmaktadır. PAC ünitelerinde akım elektrotlardan geçerken yüksek seviyede ISI oluşturur. PAC üniteleri $1800 \mathrm{mw} / \mathrm{cm}^{2}$ den fazla ışık gücüne sahiptir. ${ }^{45}$

Bunun yanı sıra PAC ışık cihazları; işlevsel olarak halojen ışılarla hemen hemen aynı özelliklere sahip olmaları, portatif olmamaları, yapılarının karmaşık olması, lambaların kullanım ömrünün sınırlı olması ve buna bağlı olarak zamanla ışık gücünde azalma meydana gelmesi, ışığı daha kompleks ve pahalı bir metotla üretmeleri sebebiyle günümüzde rutin olarak kullanılmamaktadırlar. ${ }^{45}$

\section{Lazer Işık Kaynakları}

Lazer (Light Amplification by Stimulated Emission of Radiation) ışı̆ın uyarılmış radyasyon yolu ile güçlendirilmesidir. Argon Lazer 1980'lerin başlarında kompozit rezin materyallerin polimerizasyonu amacıyla kullanılmaya başlanmıştır. ${ }^{46}$

Lazer teknolojisinde atomların enerji absorbe edip daha yüksek enerji seviyelerine çıkması özelliğinden yararlanilır. Bu enerji transferi sonucu oluşan fotonlar aynı enerji düzeyinde, aynı frekansta, aynı yönde hareket ederler. Bu nedenle lazer ışığı aynı fazda aynı frekanstadır ve birbirinden uzaklaşmaz tarzda tek bir dalga boyundadır. Böylece belli bir frekanstaki yoğun enerji miktarı küçük bir alana yönlendirilebilir. ${ }^{46,47}$

Lazer sistemleri temelde aktif ortam (lazerin uygulandığı enerjinin dalga boyunu belirler), pompa mekanizması (aktif ortamın atomlarıı uyarmak için kullanılır) ve optik yansıtıcıdan oluşur. Optik ortam iki konkav aynadan oluşur ve fotonların aktif ortam içinde sürekli olarak yansıtılmasını sağlamaktır. Lazerlerdeki çeşitliliğin sebebi aktif ortamın farkllığına bağlı olarak değişen dalga boyudur. Lazerler dalga boylarına göre;

- Ultraviyole (U.V.): 140-400 $\mu \mathrm{m}$ dalga boyu

- Görülebilir spektrum: 400-700 $\mu$ m dalga boyu,

- İnfrared (kızılötesi) spektrum: $700 \mu m^{\prime}$ den mikrodalgaya kadar giden dalga boyları olarak sıniflandırilır.

Günümüzde diş hekimliğinde polimerizasyonun sağlanması amacıyla 400- $500 \mu \mathrm{m}$ dalga boyunda ışık spektrumu ile argon lazer (457-502 $\mu \mathrm{m})$ kullanılmaktadır. Pulpa ve oral dokularda ıSı artı̧̧ı en aza indirilmiştir. ${ }^{47}$ Kompozit rezinlerin polimerizasyonu için ISI enerjisini ışık enerjisine dönüştüren argon lazer, yüksek voltajı akımın aktive ettiği inert gaz serisidir. Lazer ışığında oluşan dalga boyu genişliği halojen kaynaklardakinden daha dardır ve $470 \mu \mathrm{m}$ ye yakındır ve kısa uygulama süresine sahiptir. Bazı üreticiler kamferokinon dışındaki foto başlatııı içeren rezin esaslı kompozitlerde argon lazer kullanılmasına başlamışıı bu durumda argon lazer polimerizasyon cihazının halojen kaynaklardan daha az polimerizasyon sağladığını düşünülmektedir. ${ }^{46,48}$

Yapılan çalışmalarda argon lazer kullanımı ile yapılan polimerizasyonun polimerizasyon zamanını kısalttığı ve artık monomer miktarının ise daha az olduğu belirtilmiştir. ${ }^{48,49}$ Halojen ışık kaynakları ile karşılaştırıdığında polimerize edilen materyalin fiziksel özelliklerinin eşit olduğu gösterilmiştir. ${ }^{49}$

Argon lazer ile polimerize olmuş rezinlerde konvensiyonel ışık kaynaklarına göre daha derin 
polimerizasyon sağlanmaktadır ve daha az artık monomer bulunmaktadır. Basma dayanımı ve çekme dayanımı gibi fiziksel özellikleri artmıştır. Aşınma direnci ise hemen hemen aynıdır. ${ }^{50}$

Argon lazer kamferokinon içerikli kompozitlerde daha büyük tabaka rezin kullanılabilmesine izin vermekte, daha kısa sürede polimerizasyon sağlayabilmekte ve daha az artık monomer görülmektedir. ${ }^{51}$ Ancak oluşan bu fazla polimerizasyona bağlı olarak kırılganlıkta ve marjinal sızıntıda artış olabileceği belirtilmiştir. ${ }^{50}$ Argon lazerle $10 \mathrm{~s}$, geleneksel Işık kaynağı ile $30 \mathrm{~s}$ polimerize edilmiş kompozit rezinin yüzey ve taban sertlikleri incelenmiş ve gruplar arasında fark gözlenmemiş fakat $3 \mathrm{~mm}$ 'de taban sertliği açısından Argon lazer ile polimerizasyonda anlamlı bir fark gözlenmiştir. ${ }^{51}$

Lazer kaynaklar kullanımdan bağımsız sınırlı bir ömre sahiptir. Kaynağın değişimi teknik bilgi gerektirir ve maliyetlidir. Enerji dönüşümü sırasında enerji kaybı çoktur. Bu nedenle yaygın kullanımı yoktur. ${ }^{50,51}$ Argon lazer kullanımının pulpadaki ısı artışının görünür ışık cihazlarının neden olduğu sıcaklık artışına oranla daha az olduğu gösterilmiştir. Uygulama uçlarının pek çok hastada kullanılmasıyla çapraz enfeksiyon riski ortaya çıkar. Dezenfeksiyon işlemleri veya şeffaf bariyerler de ışık gücü yoğunluğunu azalttığı için, günümüzde tek kullanımlık ışık uçlarına ilgi giderek artmaktadır. ${ }^{50,51}$ Yeni geliştirilen argon lazer ünitelerin boyutları ve ağırlıkları azaltılmış taşınılabilirliği arttırılmıştır. Ancak maliyet açısından oldukça pahalıdır. ${ }^{50,51}$ Lazer ışığı yansır absorbe edilir ve dağılır formda olduğu için hedeflenen bölge dışında çevre dokulara da etkiler bu nedenle uygulayıcının çevre dokulara zarar verme riski vardır. Karaarslan ve ark. ${ }^{52}$ yayınına göre argon lazer ile polimerizasyon mümkün olmasına rağmen maliyetin yüksek ve hekim tecrübesizliği nedeni ile sadece polimerizasyon amaçlı lazer kullanımının klinik olarak pek mümkün görülmediğini ifade etmiştir. ${ }^{52}$

\section{SONUÇ}

Işık cihazlarının gelişimi devam ederken klinik şartlarda hekimin hangi ışık kaynağına ne kadar süre ihtiyacı olduğunu bilmesi gerekmektedir. Konvensiyonel yöntemlerle, argon lazer kıyaslandığında; argon lazer kullanımı ile yapılan polimerizasyonun, polimerizasyon zamanını kısalttığı ve artık monomer miktarının daha az olduğu bilinmektedir. Işık cihazlarının seçimin- de maliyet büyük bir etken olsa da; artık monomer oluşumu, polimerzasyon hızı ve ışık kaynağının gücü gibi etkenleri de unutmamak gerekir. Işık cihazlarındaki gelişmelere rağmen kompozit rezin uygulamalarında polimerizasyon büzülmesi ve artık monomerin kalması halen büyük sorun teşkil etmektedir.

Özge Türkoğlu: ORCID ID: 0000-0002-5167-3323

Ali Can Bulut: ORCID ID: 0000-0002-1586-7403

\section{KAYNAKLAR}

1. Rawls KJ, Esquivel-Upshaw, J. Restorative resins. In: Phillips' science of dental materials. 11th Ed. Ed: Anusavice, K.J., St. Louis: W.B. Saunders: 2003. p. 399-437.

2. Yazici AR, Muftu A, Kugel G, Perry RD. Comparison of temperature changes in the pulp chamber induced by various light curing units, in vitro. Oper Dent.2006;31:261-5.

3. Unterbrink $\mathrm{GL}$, Muessner $\mathrm{R}$. Influence of light intensity on two restorative systems. J Dent 1995; 23:183-9.

4. Mills RW, Jandt KD, Ashworth SH. Dental composite depth of cure with halogen and blue light emitting diode technology. Br Dent J 1999; 24:388-91.

5. Mills RW, UHL A, Jandt KD. High power light emitting diode (LED) arrays versus halogen light polymerization of oral biomaterials: Barcol hardness, compressive strenght and radiometric properties. Biomaterials, 2002;24:2097-103.

6. Craig RG, Powers JM. Restorative dental materials. 11th Ed. St. Louis: The C.V. Mosby Co., 2002.p. 231-85.

7. Rueggeberg FA, Ergle JW, Mettenburg DJ. Polymerization depths of contemporary light-curing units using microhardness. J Esthet Dent 2000; 12:340-9.

8. Asmussen E, Peutzfeldt A. Polymerization contraction of resin composite vs. energy and power density of light-cure. Eur J Oral Sci 2005;113:417-21.

9. Halvorson RH, Erickson RL, Davidson CL. Energy dependent polymerization of resin-based composite. Dent Mater 2002;18:463-9.

10. Price RB, Felix CA, Andreou P. Effects of resin composite composition and irradiation distance on

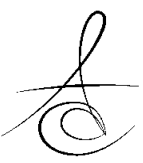


the performance of curing lights. Biomaterials. 2004;25:4465-77.

11. Correr $A B$, Sinhoreti MAC, Sobrinho LC, Tango RB, Schneider LFJ. Consani S. Effect of the increase of energy density on knoop hardness of dental composites light-cured by conventional QTH, LED and xenon plasma arc. Braz Dent J 2005;16:21824.

12. Tarle, Z, Meniga A, Knezevic A, Sutalo J, Ristic M, Pichler G. Composite conversion and temperature rise using a conventional, plasma arc and experimental blue LED curing unit. J. Oral Rehabil. 2002;29:662-7.

13. Jiménez-Planas A, Martín J, Abalos C, Llamas R. Developments in polymerization lamps. Quintessence Int 2008;39:74-84.

14. Mc Cabe JF, Walls AWG. Applied dental materials. 8th Ed. Oxford, England:Blackwell Scientific Pub.2000. p.87-178.

15. Singh KT, Ataide I, Fernandes M, Lambor TR. Light Curing Devices-A Clinical Review. J Orofac Res 2011;1:15-19.

16. Price RB, Felix CA, Andreou P. Evaluation of a secondgeneration LED curing light. J Can Dent Assoc 2003;69:66-9.

17. Kauppi, MR, Combe ECC. Polymerization of orthodontic adhesives using modern high-intensity visible curing lights. Am. J. Orthod. Dentofacial Orthop. 2003;124:316-22.

18. Anne P, Adrian L, Simon F. Effect of highirradiance light-curing on micromechanical properties of resin cements. BioMed Res Int 2016; 1: $15-9$.

19. Caughman WF, Rueggeberg FA. Shedding new light on composite polymerization. Oper Dent 2002;27:636-8.

20. Vandewalle KS, Roberts HW, Tiba A, Charlton DG. Thermal emission and curing efficiency of LED and halojen curing lights. Oper Dent 2005;30:257-64.

21. Hackman ST, Pohjola RM, Rueggeberg FA. Depths of cure and effect of shade using pulse-delay and continuous exposure photo-curing techniques. Oper. Dent. 2002;27:593-9.

22. Bouillaguet S, Caillot G, Forchelet J, CattaniLorente M, Wataha JC, Krejci I. Thermal risks from LED- and high-intensity QHT-curing units during polymerization of dental resins. J Biomed Mater Res B Appl Biomater 2005; 72:260-7.
23. Yoon TH, Lee YK, Lim BS, Kim CW. Degree of polymerization of resin composites by different light sources. J Oral Rehabil 2002;29:1165-73.

24. Yap AUJ, Soh MS. Thermal emission by different light-curing units. Oper Dent 2003;28:260-266.

25. Rahiotis C, Kakaboura A, Loukidis M, Vougiouklakis G. Curing efficiency of various types of light-curing units. Eur J Oral Sci 2004;112:89-94.

26. Ersoy M, Özel E, Gökçe K. Farklı uygulama yöntemlerinin kompozit rezinlerin mikrosertlikleri üzerine etkisi Atatürk Üniv Diş Hek Fak Derg 2007; 17: 28-31.

27. Campregher UB, Samuel SM, Fortes CB, Medina $A D$, Collares FM, Ogliari FA. Effectiveness of second-generation light-emitting diode (LED) light curing units. J Contemp Dent Pract.2007;8:35-42.

28. Kurachi C, Tuboy AM, Magalhaes DV, Bagnato VS. Hardness evulation of a dental composite polymerized with experimental LED-based devices. Dent Mater 2001;17:309-15.

29. Silva EH, Albuquerque RC, Lanza LD, Vieira GC, Peixoto RT, Alvim HH, Yoshida MI. Influence of different light sources on the conversion of composite resins. Indian J Dent Res 2011;22:7904.

30. Neumann M, Miranda WJR, Schmitt C, Rueggeberg F, Correa I. Molar extinction coefficients and the photon absorption efficiency of dental photoinitiators and light curing units. J Dent 2005; 33: 525-32.

31. Bennett AW, Watts DC. Performance of two blue light emitting diode dental curing units with distance and irradiation time. Dent Mater 2004;20: 72-9.

32. Uhl A, Mills RW, Vowles RW, Jandt KD. Knoop hardness depth profiles and compressive strength of selected dental composites polymerized with halogen and LED light curing technologies. J Biomed Mater Res 2002;63:729-38.

33. Armellin $E$, Bovesecchi $G$, Coppa P, Pasquantonio G, Cerroni L. Led curing lights and temperature changes in different tooth sites. BioMed Res Int-I 2016; 1:10-4.

34. Jandt KD, Mills RW. A brief history of LED photopolymerization. Dent Mater 2013;29:605-17.

35. Hofmann N, Hugo B, Klaiber B. Effect of irradiation type (LED or QTH) on photo-activated composite

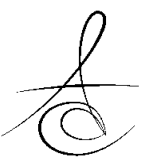


shrinkage strain kinetics, temperature rise and hardness. Eur Oral Sci 2002;110:471-9.

36. Çakmakcıoğlu Ö, Topbaş B. Farklı ışı kaynaklarının kompozit polimerizasyonuna etkisi Atatürk Üniv Diş Hek Fak Derg 2005;15:48-54.

37. Schneider LF, Consani S, Sinhoreti MA, Sobrinho LC, Milan FM. Temperature change and hardness with different resin composites and photoactivation methods. Oper Dent 2005;30:516-21.

38. Schneider LF, Cavalcante LM, Prahl SA, Pfeifer CS, Ferracane JL. Curing efficiency of dental resin composites formulated with camphorquinone or trimethylbenzoyl-diphenyl-phosphine oxide. Dent Mater 2012;28:392-7.

39. Lima AF, Formaggio SEF, Zambelli LFA, Palialol ARM, Marchi GM, Saraceni CHC, Oliveira MT. Effects of radiant exposure and wavelength spectrum of light-curing units on chemical and physical properties of resin cements. Restor Dent Endod 2016;41:271-7.

40. Hee-Min L, Sang-Cheol K, Kyung-Hwa K, NaYoung $C$. Comparison of the bonding strengths of second- and third-generation light-emitting diode light-curing units. Korean J Orthod 2016;46:36471.

41. Price RBT, Fahey J, Felix CM. Knoop microhardness mapping used to compare the efficacy of led, qth and pac curing lights. Oper Dent 2010;35:58-68.

42. Spranley TJ, Winkler M, Dagate J, Oncale D, Strother E. Curing light burns. Gen Dent 2012;60:210-4.

43. Labrie D, Moe J, Price RBT, Young ME, Felix CM. Evaluation of ocular hazards from 4 types of curing lights. J Can Dent Assoc 2011;77:116-8.

44. Roule JF, Wilson NHF, Fuzzi M. Advance in operative dentistry. Challenges of the future. Chicago: Quintessence Publishing Co. Inc.2001. p. 169-72.

45. Oesterle LJ, Newman SM, Shellhart WC. Rapid curing of bonding composite with a xenon plasma arc light. Am J Orthod Dentofacial Orthop 2001;119:610-6.

46. Rueggeberg FA, Blalock JS, Callan RS. LED curing lights - what is new? Compend Contin Educ Dent 2005;26:586-91.

47. Bektaş ÖÖ, Siso HŞ, Eren D. Işık kaynakları, polimerizasyon ve klinik uygulamalar. EÜ Dişhek Fak Derg 2006;27:117-24.
48. Hilton TJ. Direct posterior esthetic restorations. In: Fundamentals of operative dentistry: a contemporary approach. 2nd Ed Ed: Summit JB, Robbins JW, Schwartz RS. Chicago: Quintessence Publishing Co. Inc.2001.p.292-305.

49. Hicks MJ, Westerman GH, Flaitz CM, Powell GL. Surface topography and enamel-resin interface ol pit and fissure sealants following visible light and argon laser polymerization: an in vitro study. ASDC J Dent Child 2000;67:169-75.

50. Mark GF, Wayne AM. Photopolymerization of composite resin using the argon laser. J Can Dent Assoc 1999;65:447-50.

51. Sun G. The rol of lasers in cosmetic dentistry. Dent Clin North Am 2000; 44:831-50.

52. Karaarslan EŞ, Yıldırım C, Üşümez A. Restoratif tedavide lazer uygulamaları Atatürk Üniv Diş Hek Fak Derg 2010;22:340-9.

\section{Yazışma Adresi}

Dr.Ali Can Bulut

Kırıkkale Üniversitesi Diş Hekimliği Fakültesi

Protetik Diş Tedavisi Bölümü

E-mail:alicanbulut@outlook.com 